\title{
TWO NEW 1D COORDINATION POLYMERS: SYNTHESES, STRUCTURES AND PROPERTIES
}

\author{
Jian $\mathrm{Wu}^{1 *}$, Fu-Min Wang ${ }^{2}$, Jian-Qiang $\mathrm{Liu}^{3}, \mathrm{Jia}^{\mathrm{X}} \mathrm{Xi} \mathrm{Chen}^{3}$, Jia-Min $\mathrm{Wu}^{3}$, Kai-Bang $\mathrm{Li}^{1}, \mathrm{Yi}$ Wei ${ }^{1}$ \\ and Qing-Lin $\mathrm{Li}^{3}$ \\ ${ }^{1}$ Guangxi Key Laboratory of Chemistry and Engineering of Forest Products, Guangxi University \\ for Nationalities, College of Chemistry and Chemical Engineering, Nanning, Guangxi 530006, \\ China \\ ${ }^{2}$ Department of Chemistry and Chemical Engineering, Shaanxi Xueqian Normal University \\ Xian 710100, Shannxi, China \\ ${ }^{3}$ Guangdong Medical College, School of Pharmacy, Dongguan, 523808, China
}

(Received December 10, 2013; revised July 11, 2014)

\begin{abstract}
Two new coordination polymers, namely, $\left[\mathrm{Zn}(\mathrm{bi})(\mathrm{Cl})_{2}\right]_{\mathrm{n}}(\mathbf{1})$ and $\left[\mathrm{Cu}(\mathrm{L})_{2}(\mathrm{bib})\left(\mathrm{H}_{2} \mathrm{O}\right)_{2}\right]_{\mathrm{n}}(\mathbf{2})(\mathrm{bi}=$ 4,4'-bis(2-methylimidazol-1-ylmethyl)biphenyl; $\mathrm{L}=4$-(2-(4-(methoxycarbonyl)phenoxy)ethoxy)benzoic acid and bib $=2,3$-bis(4-pyridyl)butane), are synthesized and characterized. Both of $\mathbf{1}$ and $\mathbf{2}$ have 1D covalent chains, which show different conformally chain feature. 2D supremolecular rhombic and rectangle motifs are observed in 1 and 2, respectively. The $\mathrm{O}-\mathrm{H} \cdots \mathrm{O}$ and $\mathrm{C}-\mathrm{H} \cdots \mathrm{Cl}$ hydrogen-bonding interactions play a significant role in promoting the diversity of structural patterns.
\end{abstract}

KEY WORDS: Structure, Supramolecular interaction, Luminescence

\section{INTRODUCTION}

During the last decade, the number of studies related to the synthesis of crystalline porous organic-inorganic hybrid materials has grown rapidly [1-3]. The structural diversity and property employments of carboxylate polymers have been expanded by the incorporation of neutral organodiimines such as 4,4'-bipyridine [4]. The structural rigidity of benzene dicarboxyalte/N-conatining subunits can be useful to construct of porous materials, flexible subunits can form different motifs due to their ability to access numerous energetically conformations. However, flexible carboxylate and $\mathrm{N}$-donor scaf-folded coordination polymers have received less attention. Even so, the prediction and synthesis of the solid-state architectures still remain a long-term challenge for the chemists [5-10].

On the other hand, the development of supramolecular assembled chemistry has allowed the possibility to rationally design and prepare supramolecular networks. Meanwhile, many investigations indicate that the weak interaction is a powerful force for supramolecular structural assembly in crystal engineering [11-14]. Based on above consideration, we report here the syntheses, structural characterization, and spectral analyses of two new coordination polymers based on three types of organic ligands (Scheme 1), namely, $\left[\mathrm{Zn}(\mathrm{bi})(\mathrm{Cl})_{2}\right]_{\mathrm{n}}(\mathbf{1})$ and $\left[\mathrm{Cu}(\mathrm{L})_{2}(\mathrm{bib})\left(\mathrm{H}_{2} \mathrm{O}\right)_{2}\right]_{\mathrm{n}}(\mathbf{2})$. The $\mathrm{L}$ was generated from 1,3-bis(4-carboxy-phenoxy)propane under hydrothermal condition in presence of copper salt.

*Corresponding author. E-mail: wujian2007gx@126.com 


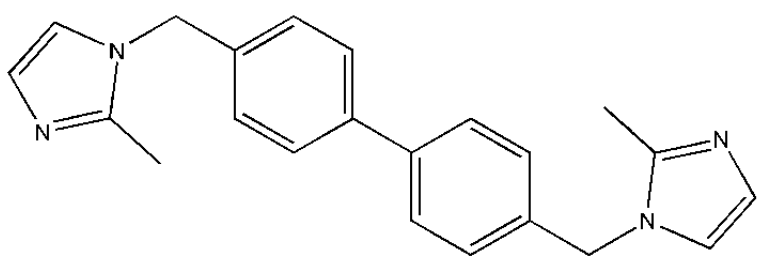

bi $=4,4$ '-bis(2-methylimidazol-1-ylmethyl)biphenyl
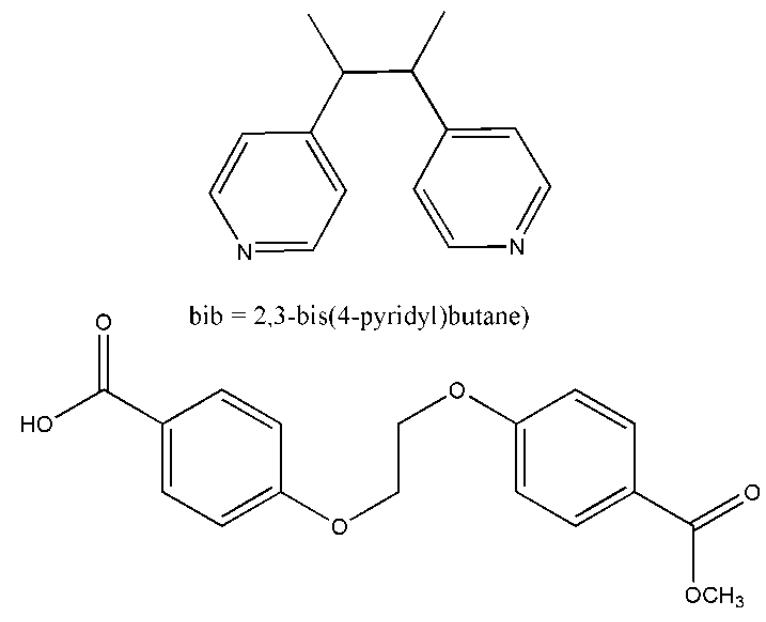

$\mathrm{L}=4-(2-(4-($ methoxycarbonyl)phenoxy)ethoxy)benzoic acid

Scheme 1. The three types of organic ligands in this work.

\section{EXPERIMENTAL}

\section{Materials and method}

All reagents were purchased from commercial sources and used as received. IR spectra were recorded with a Perkin-Elmer Spectrum One spectrometer in the region $4000-400 \mathrm{~cm}^{-1}$ using $\mathrm{KBr}$ pellets. TGA were carried out with a Metter-Toledo TA 50 in dry dinitrogen $\left(60 \mathrm{~mL} \cdot \mathrm{min}^{-1}\right)$ at a heating rate of $5{ }^{\circ} \mathrm{C} \mathrm{min}^{-1}$. X-ray powder diffraction (XRPD) data were recorded on a Rigaku RU200 diffractometer. Luminescence spectra data were recorded at an Edinburgh FLS920 phosphorimeter.

\section{X-Ray crystallography}

Single crystal X-ray diffraction analyses of the three compounds were carried out on a Bruker SMART APEX II CCD diffractometer equipped with a graphite monochromated MoK $\alpha$ radiation $(\lambda=0.71073 \AA$ ) by using $\phi / \omega$ scan technique at room temperature. The intensities were 
corrected for Lorentz and polarization effects as well as for empirical absorption based on multiscan techniques; all structures were solved by direct methods and refined by full-matrix leastsquares fitting on $F^{2}$ by SHELX-97 [15]. Absorption corrections were applied by using multiscan program SADABS [16]. The hydrogen atoms of organic ligands were placed in calculated positions and refined using a riding on attached atoms with isotropic thermal parameters 1.2 times those of their carrier atoms. The water hydrogen atoms were located from difference maps and refined with isotropic thermal parameters 1.5 times those of their carrier atoms. The compound 2 was weakly diffractors giving poor data and that we were unable to obtain better crystals despite attempt to do so, assuming that was the case. Table 1 shows crystallographic data of 1-2. Selected bond distances and bond angles are listed in Table 2. CCDC: 971716971717. These data can be obtained free of charge via www.ccdc. cam.ac.uk/conts/retrieving.html (or from the Cambridge Crystallographic Data Centre, 12 Union Road, Cambridge CB2 1EZ, UK; fax: (+44)1223-336-033; or deposit@ccdc.cam.ac.uk).

Table 1. The crystallographic data of $\mathbf{1}$ and $\mathbf{2}$.

\begin{tabular}{|l|l|l|}
\hline Complex & $\mathbf{1}$ & $\mathbf{2}$ \\
\hline Empirical formula & $\mathrm{C}_{22} \mathrm{H}_{22} \mathrm{Cl}_{2} \mathrm{~N}_{4} \mathrm{Zn}$ & $\mathrm{C}_{48} \mathrm{H}_{50} \mathrm{CuN}_{2} \mathrm{O}_{14}$ \\
\hline Formula mass & 478.71 & 942.44 \\
\hline Crystal system & Orthorhombic & Triclinic \\
\hline Space group & $P b c n$ & $P-1$ \\
\hline$a[\AA]$ & $8.899(4)$ & $7.3012(5)$ \\
\hline$b[\AA]$ & $14.460(7)$ & $11.7373(7)$ \\
\hline$c[\AA]$ & $16.930(8)$ & $13.9407(9)$ \\
\hline$\alpha\left[^{\circ}\right]$ & 90 & $74.686(5)$ \\
\hline$\beta\left[^{\circ}\right]$ & 90 & $77.195(5)$ \\
\hline$\gamma\left[^{\circ}\right]$ & 90 & $84.677(5)$ \\
\hline$V\left[\AA^{3}\right]$ & $2178.5(18)$ & $1122.85(13)$ \\
\hline$Z$ & 2 & 1 \\
\hline $\mathrm{d}_{\text {calcd }}[\mathrm{g} \cdot \mathrm{cm}$ & -3 \\
\hline$\mu\left[\mathrm{mm}^{-1}\right]$ & 1.460 & 1.394 \\
\hline$F(000)$ & 1.388 & 0.557 \\
\hline $\left.\mathrm{Reflections} \mathrm{collected}^{-1}\right]$ & 984 & 493 \\
\hline $\mathrm{R}_{\text {(int) }}$ & 10426 & 14498 \\
\hline$R_{1}, w \mathrm{R}_{2}[I>2 \sigma(I)]$ & 0.0356 & 0.0788 \\
\hline$R_{1}, w \mathrm{R}_{2}$ (all data) & $0.0370,0.1199$ & $0.0619,0.1417$ \\
\hline & $0.0527,0.1369$ & $0.1419,0.1784$ \\
\hline
\end{tabular}

\section{Synthesis of the complexes}

[Zn(bi) $\left.(\mathrm{Cl})_{2}\right]_{n}(\mathbf{1})$. A mixture of $\mathrm{ZnCl}_{2} \cdot 5 \mathrm{H}_{2} \mathrm{O}(0.0512 \mathrm{~g}), \mathrm{H}_{2}$ bce $(0.0285 \mathrm{~g})$, bi (0.0204 g), deionised water $(10 \mathrm{~mL})$ and $\mathrm{CH}_{3} \mathrm{OH}(5 \mathrm{~mL})$ was stirred in air. The $\mathrm{pH}$ of the resulting solution was adjusted to 7 using dilute $\mathrm{NaOH}(1 \mathrm{M})$ and kept at $160{ }^{\circ} \mathrm{C}$ for $72 \mathrm{~h}$ at oven, and then cooled down to $25{ }^{\circ} \mathrm{C}$. The resulting crystals formed were filtered off, washed with water and dried in air. $\mathrm{C}_{22} \mathrm{H}_{22} \mathrm{Cl}_{2} \mathrm{~N}_{4} \mathrm{Zn}$. Calcd: C, 55.19; N, 11.70; H, 4.63. Found C, 55.38; N, 11.49; H, 4.56. IR $\left(\mathrm{KBr}, \mathrm{cm}^{-1}\right)$ : 3019(m); 1595(m); 1434(s); $1284(\mathrm{~m}) ; 1105(\mathrm{~m}) ; 843(\mathrm{~s}) ; 756(\mathrm{~s})$.

$\left[\mathrm{Cu}(\mathrm{L})_{2}(\text { bib })\left(\mathrm{H}_{2} \mathrm{O}\right)_{2}\right]_{n}$ (2). A mixture of $\mathrm{Cu}\left(\mathrm{NO}_{3}\right)_{2} \cdot 6 \mathrm{H}_{2} \mathrm{O}(0.0411 \mathrm{~g}), \mathrm{H}_{2} \mathrm{~L}(0.0291 \mathrm{~g})$, bib $(0.0254$ $\mathrm{g})$, deionised water $(10 \mathrm{~mL})$ and $\mathrm{CH}_{3} \mathrm{OH}(5 \mathrm{~mL})$ was stirred in air. The $\mathrm{pH}$ of the resulting solution was adjusted to 7 using dilute $\mathrm{NaOH}(1 \mathrm{M})$ and kept at $160{ }^{\circ} \mathrm{C}$ for $72 \mathrm{~h}$ at oven, and then cooled down to $25^{\circ} \mathrm{C}$. The resulting crystals formed were filtered off, washed with water and dried in air. $\mathrm{C}_{48} \mathrm{H}_{50} \mathrm{CuN}_{2} \mathrm{O}_{14}(942.44)$ Calcd: $\mathrm{C}, 61.17 ; \mathrm{N}, 2.97 ; \mathrm{H}, 5.35$. Found: $\mathrm{C}, 60.88 ; \mathrm{N}$, 
2.71; H, 5.20. IR (KBr, $\left.\mathrm{cm}^{-1}\right)$ : 3428(vs), 3085(m); 1659(m); 14211(s), 1120(m), 1011(m), 859(m), 711(m).

\section{RESULTS AND DISCUSSION}

$\left[\mathrm{Zn}(\mathrm{bi})(\mathrm{Cl})_{2}\right]_{n}(\mathbf{1})$

As shown in Figure 1a, each ligand coordinates to two $\mathrm{Zn}$ (II) ions and each $\mathrm{Zn}$ (II) ion is coordinated by two bi to generate a $1 \mathrm{D}$ zigzag chain. The $\mathrm{Zn}(\mathrm{II})$ is in a distorted tetrahedral geometry with its coordination sphere completed by two $\mathrm{Cl}$ anions. The two $\mathrm{Zn}$ (II)-Cl distances are longer than that of $\mathrm{Zn}-\mathrm{N}$ bond distances (Table 2). Each bi ligand possesses a crystallography inversion center that is situated in the middle of the central benzene ring. As a result, each adopts an anti-syn conformation. The imidazole rings are almost perpendicular to the benzene ring, with a dihedral angle of $83.55^{\circ}$. The adjacent $\mathrm{Zn}$ (II) are connected by bi into a 1D helical chain, as shown in Figure 1b-1d.

Table 2. Selected bond distances $(\AA)$ and angles $\left(^{\circ}\right)$.

\begin{tabular}{|llll|}
\hline \multicolumn{5}{|c|}{$\mathbf{1}$} \\
\hline Zn1-N1\#1 & $2.011(3)$ & Zn1-C11\#1 & $2.2310(10)$ \\
\hline N1-Zn1-N1 & $105.11(15)$ & N1-Zn1-Cl1 & $103.92(8)$ \\
\hline Cl1-Zn1-C11 & $114.24(6)$ & & \\
\hline$\# 1:-x, y,-Z+1 / 2$. \\
\hline & & & \\
\hline Cu1-O1\#1 & $1.952(3)$ & Cu1-N1\#1 & $1.994(3)$ \\
\hline Cu1-O1W\#1 & $2.621(5)$ & O1-Cu1-O1 & 180 \\
\hline O1W-Cu1-O1W & 180 & N1-Cu1-O1 & $91.26(13)$ \\
\hline N1-Cu1-N1 & 180 & & \\
\hline$\# 1:-x, 1-y, 1-z$. & & & \\
\hline
\end{tabular}

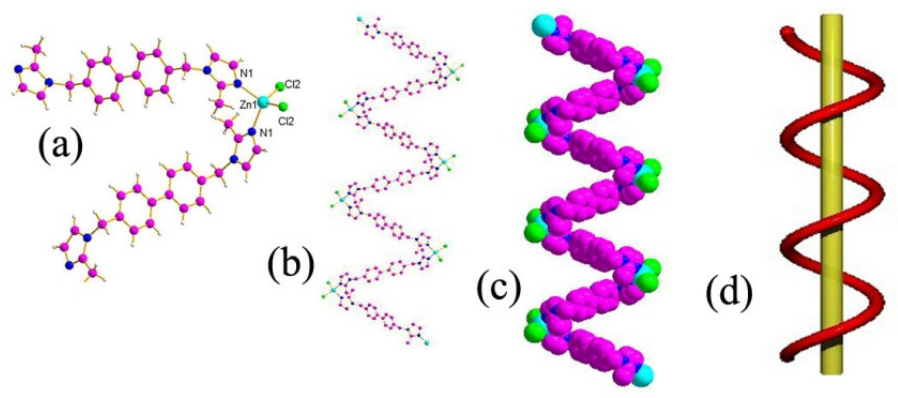

Figure 1. (a) View of the coordination geometry for $\mathrm{Zn}(\mathrm{II})$ ion; (b) the 1D helical chain; (c) the filling result for 1D chain; and (d) the schematic picture for 1D helical chain.

The hydrogen contacts mainly determine the crystal packing shown in Figure 2a. These parallel polymeric chains are connected through extensive hydrogen bonds $\mathrm{C}-\mathrm{H} \cdots \mathrm{Cl}$ to form a 2D supramolecular net (Figure $2 b$ ). 
(a)

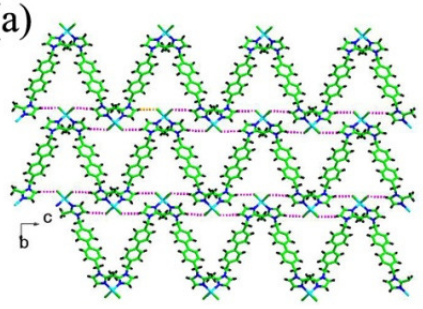

(b)

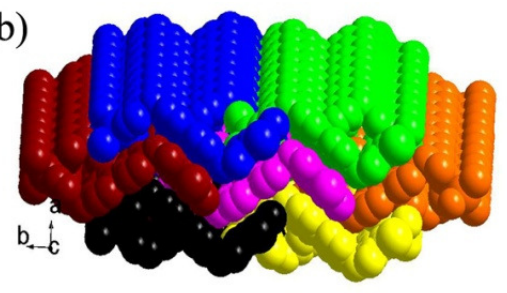

Figure 2. (a) View the 2D grid sheet constructed by supramolecular interactions; (b) view of the packing interaction among adjacent sheets.

$\left[\mathrm{Cu}(\mathrm{L})_{2}(\mathrm{bib})\left(\mathrm{H}_{2} \mathrm{O}\right)_{2}\right]_{n}(2)$

X-ray crystallographic data reveal that complex 2 is made up of a one-dimensional squarewave-like chain. Here each $\mathrm{Cu}$ (II) atom is coordinated by two oxygen atoms from two synmmetric water molecules, two carboxyl oxygen atoms $(\mathrm{O} 1, \mathrm{O} 1 \mathrm{~A})$ and two nitrogen atom from bib ligands, forming a octahedral coordination geometry (Figure 3). The $\mathrm{Cu}-\mathrm{O}$ bond lengths range from $1.952(3)$ to $2.620(8) \AA$, and the $\mathrm{Cu}-\mathrm{N}$ distance is $1.994(3) \AA$, comparable to those in the six coordinated $\mathrm{Cu}(\mathrm{II})$ complexes. The $\mathrm{L}$ was in situ generated from 1,3-bis(4carboxy-phenoxy)propane. One carboxyl group in 1,3-bis(4-carboxy-phenoxy)propane has joined a methylation process in the presence of copper resource, in which has been observed in reported complexes.

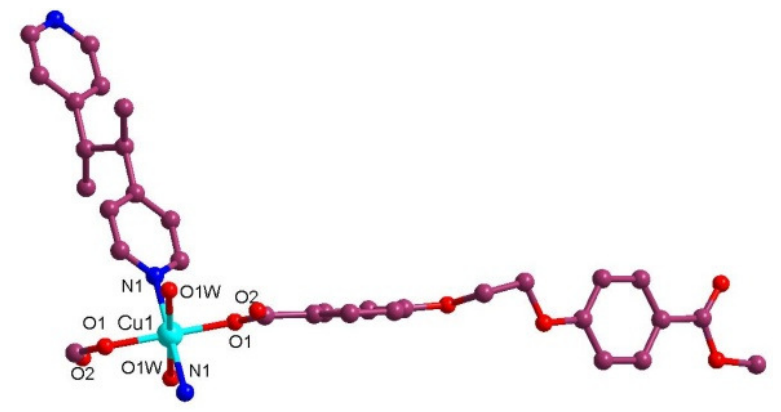

Figure 3. View of the coordination mode for $\mathrm{Cu}(\mathrm{II})$ atom in $\mathbf{2}$.

The bib taking as monodentate mode binds to $\mathrm{Cu}(\mathrm{II})$ ions into a $1 \mathrm{D}$ chain. These kernels chains are oriented parallel to the $b$ crystal axis. More interestingly, a 2D supramolecular motif could be formed by the extensive hydrogen bonds $\mathrm{O}-\mathrm{H} \cdots \mathrm{O}$ between coordinated water molecule and methoxy group as shown in Figure 4. 


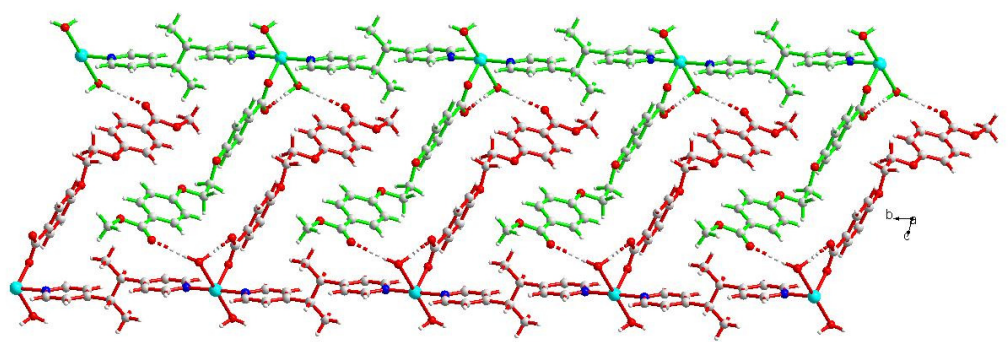

Figure 4. View of the 2-D grid network directed by $\mathrm{O}-\mathrm{H} \cdots \mathrm{O}$ hydrogen bonding interactions.

Barbour and his co-workers reported a series of $\left[\mathrm{M}_{2} \mathrm{Cl}_{4} \mathrm{bi}_{2}\right] \cdot 2 \mathrm{CH}_{3} \mathrm{OH}(\mathrm{M}=\mathrm{Cd}, \mathrm{Zn}$ and $\mathrm{Co})$, which each complex the two metal ions are tetrahedrally coordinated to two chloride anions and two C-shaped bridging ligands. Metallocycles stack to form columns, and that this packing mode creates solvent-filled pockets between adjacent metallocycles [17-18]. Each metallocycle shares cavities with both of its neighbors. The difference between the $\mathbf{1}$ and $\left[\mathrm{M}_{2} \mathrm{Cl}_{4} \mathrm{bi}_{2}\right] \cdot 2 \mathrm{CH}_{3} \mathrm{OH}$ may be induced by the template effect. Although the 1,2-bis(4-carboxy-phenoxy)ethane (bce) ligand does not crystallize and coordinates to metal ions from the compound. But if the bce does not use as starting material, the crystal samples could not be obtained. Thus, the bce molecule may take as template agent in self-assembly of the title compound $\mathbf{1}$.

\section{TGA and XPRD analysis of complexes 1 and 2}

To study the stability of the polymer, thermogravimetric analyses (TGA) of complexes $\mathbf{1 - 2}$ were performed (Figure S1). The TGA result of 1 shows only one weight loss step. The weight loss began at $110{ }^{\circ} \mathrm{C}$ and completed at $755^{\circ} \mathrm{C}$. The observed weight loss of $72.4 \%$ is corresponding to the loss of the bi (calcd $71.6 \%$ ). The final mass remnant of $22.8 \%$ may be consistent with $\mathrm{ZnO}$ (17.2\% predicted). The TGA result of $\mathbf{2}$ shows two weight loss steps. The first weight loss began at $65{ }^{\circ} \mathrm{C}$ and completed at $175{ }^{\circ} \mathrm{C}$, corresponding to the loss of coordinated water molecules (calcd $3.8 \%$ ). Soon after, the elimination of $\mathrm{L}$ and bib ligands was observed. The remnant at $780{ }^{\circ} \mathrm{C}(26.2 \%)$ is indicative of a mixture of $\mathrm{CuCO}_{3}$ and $\mathrm{CuO}$.

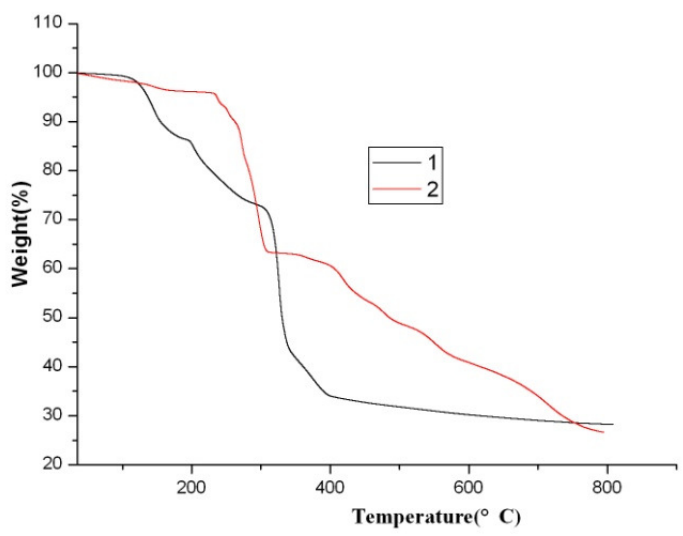

Figure S1. The diagram of TGA for compounds $\mathbf{1}$ and $\mathbf{2}$.

Bull. Chem. Soc. Ethiop. 2014, 28(3) 
Additionally, to confirm the phase purity and stability of compound 1, the original samples were both characterized by X-ray powder diffraction (XRPD). The XRPD experimental and computer-simulated patterns of 1-2 are shown in Figure S2. Although the experimental patterns have a few unindexed diffractions lines and some are slightly broadened in comparison to those simulated from single-crystal models, it can still to be considered that the bulk synthesized materials and as-grown crystal are homogeneous for compounds 1-2.
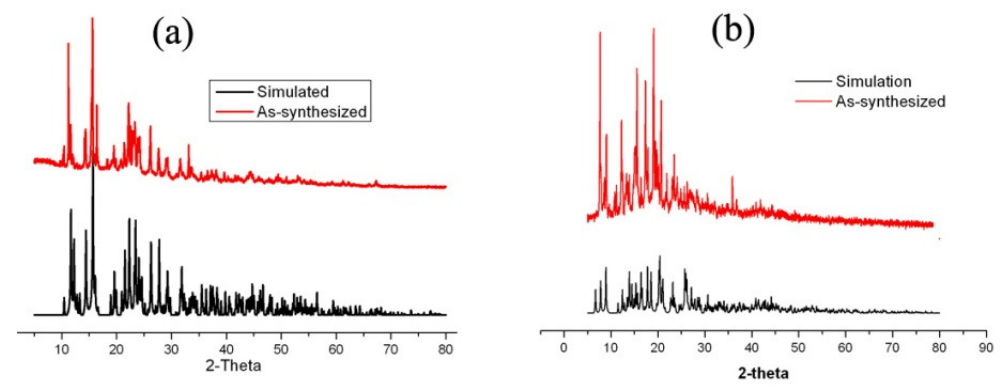

Figure S2. Comparison of XRPD patterns of the simulated pattern from the single-crystal structure determination and the as-synthesized product in compounds $\mathbf{1}$ and $\mathbf{2}$.

Coordination polymers with $\mathrm{d}^{10}$ metal centers have been investigated for their fluorescent properties and potential applications as fluorescent-emitting materials, such as light-emitting diodes (LEDs) [19]. Therefore, the complex 1 were studied in the solid-state at room temperature. Excitation of the microcrystalline sample at $312 \mathrm{~nm}$ leads to the generation of fluorescent emission, with the peak maxima occurring at $371 \mathrm{~nm}$ for $\mathbf{1}$, as shown in Figure 5. To further understand the origin of these emission bands, the ligand bi displays photoluminescence with emission maximum at $323 \mathrm{~nm}\left(\lambda_{\mathrm{ex}}=300 \mathrm{~nm}\right)$ [20]. Due to its $\mathrm{d}^{10}$ electronic configuration, $\mathrm{Zn}$ (II) is difficult to oxidize or reduce, so the emission here is neither metal-to-ligand charge transfer nor ligand-to-metal charge transfer. The profile and position of the emission band of $\mathbf{1}$ is similar to those observed in the free bi ligand, they may be assigned mainly to the intraligand transition of bi which is modified by metal coordination. The emission in the blue region suggests that 1 could be taken as potential blue-light-emitting materials [21].

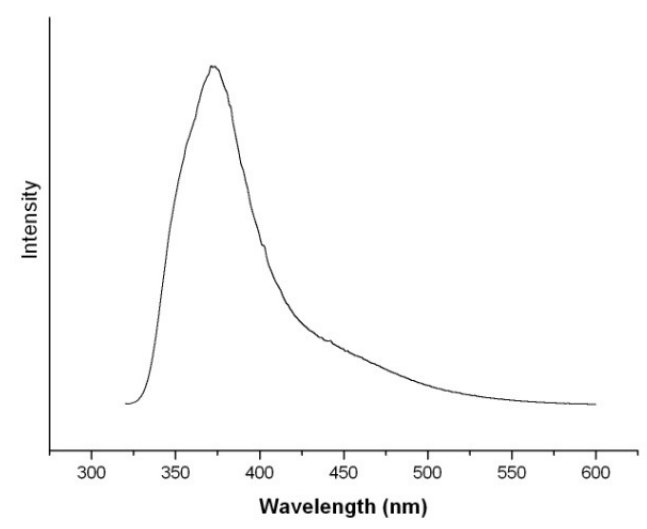

Figure 5. View of the fluorescence spectrum of $\mathbf{1}$ at room temperature. 


\section{CONCLUSION}

In summary, two new 1D polymers were constructed by organic linkers. The difference in the structures reveals that the auxiliary ligand may play a role in modulating the resulting motifs.

Further systematic work towards fabricating more polymers with interesting structures and functionalities using flexible ligands is in progress.

\section{ACKNOWLEDGMENTS}

This work was partially supported by the grants from the Technologies R \& D program of Zhanjiang (2011C3108013 and 2012C3106016), Guangxi University for Nationalities College Students' Innovative Entrepreneurship Training Program.

\section{REFERENCES}

1. Couck, S.; Denayer, J.F.M.; Baron, G.V. J. Am. Chem. Soc. 2009, V131, 6326.

2. Accorsi, G.; Listorti, A.; Yoosaf, K. J. Chem. Soc. Rev. 2009, V38, 1690.

3. Perry, I.V.; Perman, J.A.; Zaworotko, M.J. J. Chem. Soc Rev. 2009, V38, 1400.

4. Liu, J.Q.; Hu, W.X.; Wu, T. Synth. React. Chem. 2010, V41, 479.

5. Montney, M.R.; Krishnan, S.M.; Patel, N.M.; Supkowski, R.M.; LaDuca, R.L. Cryst. Growth Des. 2007, V7, 1145.

6. Mondal, R.; Bhunia, M.K., Dhara, K., Cryst. Eng. Comm. 2008, V10, 1167.

7. Farha, O.K.; Malliakas, C.D.; Kanatzidis, M.G.; Hupp, J.H. J. Am. Chem. Soc. 2010, V132, 950.

8. Ghosh, R.; Jana, A.D.; Pal, S.; Mostafa, G.; Fun, H.-K.; Ghosh, B.K. Cryst. Eng. Comm. 2007, 9, 353.

10. Eddaoudi, M.; Moler, D.B.; Li, H.; Chen, B.; Reinecke, T.M.; O’Keeffe, M.; Yaghi, O.M. Acc. Chem. Res. 2001, V34, 319.

11. Wu, C.D.; Hu, A.G.; Zhang, L.; Lin, W.B. J. Am. Chem. Soc. 2005, V127, 8940.

12. Wen, L.; Lu, Z.; Lin, J.; Tian, Z.; Zhu, H.; Meng, Q. Cryst. Growth Des. 2007, V7, 93.

13. Su, Z.; Fan, J.; Okamura, T.; Sun, W.Y.; Ueyama, N. Cryst. Growth Des. 2010, V10, 3515.

14. Zhang, L.P.; Ma, J.F.; Yang, J.; Pang, Y.Y.; Ma, J.C. Inorg. Chem. 2010, V49, 1535.

15. Sheldrick, G.M. SHELXL-97: Program for Structure Determination and Refinement, University of Göttingen: Göttingen, Germany; 1997.

16. Sheldrick, G.M. SADABS 2.05, University of Göttingen: Germany; 2002.

17. Jacobs, T.; Lloyd, G.O.; Gertenbach, J.A.; Müller-Nedebock, K.K.; Esterhuysen, C.; Barbour, L.J. Angew. Chem. Int. Ed. 2012, V51, 1.

18. Jacobs, T.; Barbour, L. New. J. Chem. 2013, V37, 71.

19. Chen, W.J.; Wang, Y.; Chen, C.; Yue, Q.; Yuan, H.M.; Chen, J.S.; Wang, S.N. Inorg. Chem. 2003, V42, 944.

20. Sun, D.; Yan, Z.H.; Deng, Y.K, Yuan, S.; Wang, L.; Sun, D.F. Cryst. Eng. Comm. 2012, V14, 7856.

21. Yi, X.Y.; Fang, H.C.; Gu, Z.G.; Zhou, Z.Y.; Cai, Y.P.; Tian, J.; Thallapally, P.K. Cryst. Goeth Des. 2011, V11, 2824. 